The Ahmed

JC Das, Z Chaudhuri, P Sharma and S Bhomaj

\section{Glaucoma Valve in \\ Refractory \\ Glaucoma: \\ experiences in Indian Eyes}

Eye (2005) 19, 183-190. doi:10.1038/sj.eye.6701447

Published online 16 July 2004

Keywords: Ahmed Glaucoma Valve; refractory glaucoma; intraocular pressure; aqueous drainage devices

\section{Introduction}

Aqueous drainage devices (ADD) have now assumed an important place in our surgical armamentarium for the treatment of complicated and refractory glaucomas both as a primary surgical modality ${ }^{1-3}$ and as a secondary procedure where trabeculectomy with or without adjunctive antimetabolite therapy has either failed or is reported to have a very low chance of success. ${ }^{1,4-10}$ The latter group consists of paediatric glaucomas, ${ }^{11-18}$ neovascular glaucomas, ${ }^{19}$ and a variety of glaucomas associated with low success after filtration surgery in conditions such as uveitis, ${ }^{20-22}$ aphakia, $^{23}$ pseudophakia, ${ }^{23}$ post-vitreoretinal surgery, ${ }^{23-24}$ and postpenetrating keratoplasty ${ }^{25-28}$ surgery.

Glaucoma drainage implants that have been used extensively include the nonrestrictive glaucoma drainage devices like Molteno implant, the Baerveldt implant and the Schocket tube shunt, and the valved, restrictive drainage devices like the Krupin Denver Valve and the Ahmed Glaucoma Valve implants. ${ }^{1}$ A glaucoma drainage device with a valve is designed to reduce the incidence of postoperative hypotony although the final outcome in terms of long term reduction in the intraocular pressures (IOPs) has been found to be better with the nonvalved devices in some studies. ${ }^{7}$ This study describes our clinical experiences with the
Guru Nanak Eye Centre New Delhi 110 002, India

Correspondence:

Z Chaudhuri, E-310,

Purvasha, Anand Lok Society Mayur Vihar Phase-1 New Delhi 110091, India Tel: + 9101122759613 Fax: +9101122792342 Email: drzia@

bol.net.in,

ziachaudhuri@

hotmail.com

Received: October 2003 Accepted: 29 December 2003

Published online: 16 July 2004

The above study was conducted in Guru Nanak Eye Centre, Maulana Azad Medical College, University of Delhi, New Delhi, India. No grants or sponsorships have been requisitioned for this study. The authors do not have any proprietary or financial interest in any product or procedure mentioned in this manuscript 
Ahmed Glaucoma Valve implant in Indian eyes with glaucoma that was refractory to conventional medical/ laser and surgical treatment.

\section{Materials and methods}

A retrospective analysis of 122 eyes of 122 patients with glaucoma uncontrolled by medications and previous glaucoma laser/surgical interventions, undergoing glaucoma surgery with the Ahmed Glaucoma Valve implant (model S-2 with surface area of $185 \mathrm{~mm}^{2}$, New World Medical Inc. , Rancho Cucamonga, CA, USA) at the Glaucoma Services Centre, Guru Nanak Eye Centre, New Delhi between January 1996 and December 1999 was performed. Only one surgeon (JCD) performed all the surgeries. In the present study group, there were no patients in whom the Ahmed Valve was implanted as a primary procedure irrespective of the clinical diagnosis.

Documentation of the following information was carried out for each patient regarding: age, gender, detailed clinical history along with general physical, and systemic examination; a comprehensive ocular examination including quantitative recording of best corrected visual acuity (BCVA) wherever possible using Snellens charts (in paediatric patients in the age group of 3-5 years who were unable to read the Snellens chart, standard HOTV optotypes at $3 \mathrm{~m}$ were used to record the visual acuity), a thorough anterior and posterior segment examination, IOP measurement with Goldmann applanation tonometer or Perkins tonometer (for paediatric patients); and gonioscopy with a Goldmann single mirror gonioprism, measurement of anterior chamber depth by ultrasound 'A' scan technique using the Humphrey biometer (model 820 REV.G), and recording of visual fields using automated perimetry by Humphrey field analyser (model HFA II 750-5751-A10.1) wherever possible.

\section{Surgical method}

The Ahmed Glaucoma Valve implantation procedure was performed under peribulbar anaesthesia in adults and under general anaesthesia in paediatric patients. The conjunctiva was undermined posteriorly by blunt dissection in the superotemporal quadrant, in all cases to create a winged fornix-based conjunctival flap. A traction suture was passed under the belly of superior rectus and lateral rectus and the globe was rotated as convenient to the surgeon. The Ahmed Glaucoma Valve implant was irrigated with $2 \mathrm{ml}$ of balanced saline solution (BSS, Alcon, Fort Worth, USA) through the tubing to open the valve mechanism.

The plate was then secured to the superficial sclera using two interrupted nonabsorbable sutures of 5-0
Merseline posterior to the insertions of the rectus muscles with the anterior edge of the explant at least $8 \mathrm{~mm}$ posterior to the limbus. These sutures were applied to prevent the migration of the plate and therefore of the tube. The tube was trimmed to extend from 1 to $3 \mathrm{~mm}$ beyond the posterior surgical limbus. Before inserting the tube into the anterior chamber a $6 \times 8 \mathrm{~mm}^{2}$ rectangular partial thickness, limbus-based scleral flap was dissected. A paracentesis opening was made at the limbus in the inferotemporal quadrant with a sharp tapered blade, and viscoelastic agent (sodium hyaluronate 1.4\%) was used to deepen the anterior chamber. A 23-gauge needle was used to enter the posterior surgical limbus parallel to the iris plane and the anterior chamber in the superotemporal quadrant. If a peripheral iridectomy was present from a previous surgery, the needle tract was placed slightly to one side of the iridectomy. This modification in technique, with reference to the method described in the literature, ${ }^{4,5}$ was made due to the lack of easy availability of donor corneoscleral grafts in our hospital set-up. In patients with aphakic and pseudophakic glaucoma who had vitreous in the anterior chamber, an anterior vitrectomy was performed prior to tube placement. The tube was inserted with a smooth forceps through the needle tract ensuring that no iris or corneal touch was present. The tube was then secured against the sclera using a figure of eight suture of 9-0 nylon. The scleral flap was approximated at the two posterior corners with a 10-0 nylon suture. Two running sutures of 8-0 polyglactin (vicryl) were used to secure the conjunctiva and Tenon layers to peripheral cornea and to close the two wing incisions, respectively. The anterior chamber was then deepened with balanced salt solution and the viscoelastic was reaspirated as much as possible via the paracentesis opening. Subconjunctival injections of antibiotics and corticosteroids were given at the conclusion of surgery.

We used viscoelastics to deepen the chamber as a corollary to the modification in our surgical technique. Owing to the frequent nonavailability of donor corneoscleral grafts in our hospital set-ups, we inserted the Ahmed valve tube after dissecting out a partial thickness scleral flap (like a trabeculectomy flap). Under the assumption that the partially dissected scleral bed would also act as a sieve for the egression of the aqueous resulting in greater hypotony, we deepened the anterior chamber with viscoelastics while performing the procedure and with BSS subsequently as mentioned above.

Postoperatively, all patients were put on topical antibiotic-steroid drops, which was tapered slowly over the course of 4-8 weeks. Antiglaucoma medications were removed or added as per the IOP and the clinical status of the operated eye. All eyes were examined at 1 day, 1 
week, 2 weeks, 1 month, 3 months, 6 months (or more often if clinically indicated), and then periodically at approximately 1-3 month intervals, depending on the patient's IOP and clinical status up to at least 1 year after surgery. All the parameters studied for the preoperative evaluation were documented on each follow-up wherever possible and decisions to start postoperative antiglaucoma medications or to perform other surgeries were taken accordingly.

The primary outcome variable was considered to be successful control of the elevated IOPs after surgery. Absolute success was defined as an IOP less than or equal to $22 \mathrm{mmHg}$ and more than $5 \mathrm{mmHg}$ with at least a $30 \%$ reduction in IOP from the preoperative levels with no additional glaucoma surgeries or visually devastating complications postoperatively. Although postoperative use of antiglaucoma medications was not a criterion for absolute success or failure, qualified success was defined as IOP less than $22 \mathrm{mmHg}$ and more than $5 \mathrm{mmHg}$ with the use of antiglaucoma medications. Till the IOP was controlled by a maximum of 2 topical and/or 1 systemic antiglaucoma medication the surgery was not considered to be a failure. Systemic antiglaucoma medications were used subsequent to the use of the topical medications.

The last follow-up was noted as the last time the patient was seen or the time at which the surgery failed by our success criteria.

The data were statistically evaluated using student's $t$ test and paired $t$-test for quantitative data and Pearson's $\chi^{2}$ test for qualitative data as indicated and the cumulative probability of success was examined by Kaplan-Meier life-table analysis.

\section{Results}

The characteristics of the patients in the study are summarized in Table 1. A total of 122 eyes of 122 patients undergoing glaucoma drainage surgery with the Ahmed valve as a secondary procedure between January 1996 and December 1999 were included in this study. Patients ranged in age from 1.5 to 92 years with a median age of 50 years. In all, 30 patients $(24.59 \%)$ were younger than 12 years (paediatric glaucoma). All the glaucomatous eyes had undergone at least one previous glaucoma filtering surgery before the aqueous drainage device insertion. The average number of glaucoma surgeries performed on each eye before the Ahmed Glaucoma Valve implant was inserted was $2.07 \pm 1.07$. Of 122,60 $(49.18 \%)$ eyes had undergone at least one laser intervention in the form of $\mathrm{Nd}$ : YAG laser peripheral iridotomy/argon laser trabeculoplasty depending upon the type of glaucoma. All patients with congenital glaucoma had undergone trabeculotomy or trabeculotomy with trabeculectomy at least once prior to
Table 1 Demographics of patient population studied

\begin{tabular}{lc}
\hline & No \\
\hline Age in years, mean \pm SD ( $n=122$ patients) & $44.40 \pm 24.02$ \\
No. of paediatric patients (<12 years) & 30 \\
Gender ( $n=122$ patients) & 60 \\
$\quad$ Male & 62 \\
Female & \\
Glaucoma diagnosis ( $\boldsymbol{n}=\mathbf{1 2 2}$ eyes) & 39 \\
Primary open-angle glaucoma & 30 \\
Chronic angle closure glaucoma & 18 \\
Congenital glaucoma & 08 \\
Neovascular glaucoma & 07 \\
Aphakic glaucoma & 07 \\
Post-traumatic glaucoma & 04 \\
Pseudophakic glaucoma & 03 \\
Aniridic glaucoma & 03 \\
Uveitic glaucoma & 02 \\
Post penetrating keratoplasty glaucoma & 01 \\
Sturge-Weber syndrome & \\
Frequency of type of glaucoma surgery/ & \\
laser intervention ( $\boldsymbol{n}=\mathbf{2 5 3}$ ) & \\
Trabeculotomy & 23 \\
Trabeculectomy \pm mitomycin C & 45 \\
Laser peripheral iridotomy & 15 \\
Argon laser trabeculoplasty & \\
\hline
\end{tabular}

Ahmed valve implantation. In four patients with aphakic glaucoma who had vitreous in the anterior chamber, an anterior vitrectomy was performed prior to tube placement. The most common diagnoses were failed trabeculectomy for primary open angle glaucoma (39 eyes, $31.96 \%$ ), failed trabeculectomy after chronic angle closure glaucoma (30 eyes, $24.59 \%$ ), and failed surgeries for congenital glaucoma (18 eyes, $14.75 \%$ ).

The mean preoperative IOP was $31.47 \pm 7.86 \mathrm{mmHg}$ with $2.83 \pm 0.72$ antiglaucoma medications. The preoperative antiglaucoma medications used usually comprised Timolol maleate $0.5 \%$ and Pilocarpine Nitrate $2 \%$. Other topical medications used were Brimonidine tartarate $0.2 \%$ and Latanoprost $0.005 \%$. The most common systemic medications used were oral carbonic anhydrase inhibitors.

Postoperatively, the mean IOP at last follow up for all eyes was $17.29 \pm 3.79 \mathrm{mmHg}$ with $0.75 \pm 0.80$ antiglaucoma medications. The mean IOP postoperatively was lower than the baseline preoperative IOP for all individual time periods examined postoperatively $(P<0.001$ at 2 weeks $(n=122), 1$ month $(n=122), 3$ months $(n=122), 6$ months $(n=70), 12$ months $(n=65), 18$ months $(n=60)$, and 24 months $(n=50))$, and the mean number of postoperative glaucoma medications was also less than preoperative values for these same time periods $(P<0.001)$. By 3 months postoperatively, both the IOP and number of glaucoma medications reached essentially plateau levels; 
VARIATION OF INTRAOCULAR PRESSURE WITH TIME

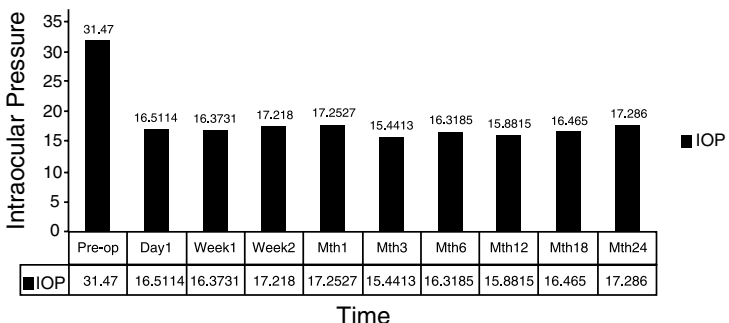

Figure 1 Mean postoperative IOP plotted over time showed a marked decrease from the preoperative IOP. A 'hypertensive phase' was conspicuously absent.

no clear 'high pressure phase' was identified in postoperative IOP (Figure 1). The mean postoperative central anterior chamber depth was $2.32 \pm 0.43 \mathrm{~mm}$. (preoperative being $2.45 \pm 0.41 \mathrm{~mm} ; P>0.05$ ) at last follow-up. There was no significant change in the mean postoperative central anterior chamber depth from the preoperative values at each follow up. Transient shallowing was seen in the immediate postoperative period in four patients having postoperative hypotony, and in two other patients having postoperative wound leak and choroidal effusion, all of which resolved either spontaneously or after minor surgical interventions. The follow-up time ranged from 3 to 24 months with a mean follow-up of $12.51 \pm 8.37$ months. There was a dropout rate of $42.62 \%$ in patient follow-up between 3 and 6 months after surgery.

Of $122,110(90.16 \%)$ eyes were considered successful at the time of last examination and $52(42.6 \%)$ out of 122 eyes required no antiglaucoma medications postoperatively till the time of their last follow-up. The reduction from the preoperative IOP at last follow up was $45.05 \%$ (Figure 1).

Any patient who came under the preview of having had a successful surgery required no systemic antiglaucoma medication as per records. These medications were, however, extensively used in eyes considered to be surgical failures (Table 2) where the average number of medications used were $2.03 \pm 0.89$ at the last follow-up. The difference between the postoperative medications used in the two groups considered to be surgical successes and failures was significant $(P<0.001)$. The average time when the surgery was considered to be a failure ranged between 2 and 14 months postoperative with an average of $8.26 \pm 1.22$ months. Most of the failures were cases of refractory and complicated glaucomas and inadequate control of the IOP in spite of maximum medical therapy was the most common cause of the failure. These cases comprised three cases of neovascular glaucoma, three of chronic angle closure glaucoma, two with uveitic glaucoma, two with congenital glaucoma, and two with aphakic glaucoma (Table 2). Except for a patient with neovascular glaucoma secondary to Eale's disease who developed retinal detachment, other failed cases maintained stable vision and optic nerve status, and IOP was controlled by repeat trabeculectomy in two cases of chronic angle closure glaucoma and cycloablative procedures in the rest. Repeat Ahmed Glaucoma Valve implant insertion surgery was not performed in any case. There was no correlation between failure rate and age at surgery, gender, lens status, and postoperative complications. However, we observed that no patient with the initial diagnosis of primary open-angle glaucoma was considered to be a failure in the period of follow-up.

In the paediatric subgroup (younger than 12 years, $n=30$ ), the mean IOP was reduced from a preoperative mean of $32.4 \pm 4.5$ to $16.60 \pm 4.4 \mathrm{mmHg}$ at 24 months postoperatively $(P<0.05)$ with an overall cumulative success rate of $85.2 \%$ at 12 months and $82.1 \%$ at 24 months.

Table 2 Failures after Ahmed Glaucoma Valve placement

\begin{tabular}{|c|c|c|c|c|c|}
\hline Sl.no. & Glaucoma diagnosis & Age/sex & No. of previous surgeries & Months to failure & Reason for failure \\
\hline 1 & Neovascular & 85/Male & 2 & 3 & IOP $>22 \mathrm{mmHg}$ (Inadequate control) \\
\hline 2 & Neovascular & 76/Female & 2 & 3 & IOP $>22 \mathrm{mmHg}$ (Inadequate control) \\
\hline 3 & Neovascular (Eale's) & 17/Male & 1 & 3 & RD with NLP \\
\hline 4 & Chronic angle closure & 28/Male & 1 & 6 & $\mathrm{IOP}>22 \mathrm{mmHg}$ (Inadequate control) \\
\hline 5 & Chronic angle closure & 54/Female & 1 & 12 & IOP $>22 \mathrm{mmHg}$ (Inadequate control) \\
\hline 6 & Chronic angle closure & 64/Female & 2 & 18 & IOP $>22 \mathrm{mmHg}$ (Inadequate control) \\
\hline 7 & Uveitic & 12/Male & 1 & 1 & $\mathrm{IOP}>22 \mathrm{mmHg}$ (Inadequate control) \\
\hline 8 & Uveitic & 65/Male & 1 & 3 & $\mathrm{IOP}>22 \mathrm{mmHg}$ (Inadequate control) \\
\hline 9 & Congenital & 2/Male & 2 & 6 & $\mathrm{IOP}>22 \mathrm{mmHg}$ (Inadequate control) \\
\hline 10 & Congenital & 2/Female & 1 & 12 & IOP $>22 \mathrm{mmHg}$ (Inadequate control) \\
\hline 11 & Aphakic & 60/Male & 2 & 24 & $\mathrm{IOP}>22 \mathrm{mmHg}$ (Inadequate control) \\
\hline 12 & Aphakic & 70/Female & 2 & 12 & $\mathrm{IOP}>22 \mathrm{mmHg}$ (Inadequate control) \\
\hline
\end{tabular}

IOP,intraocular pressure; RD, retinal detachment; NLP, No light perception. 


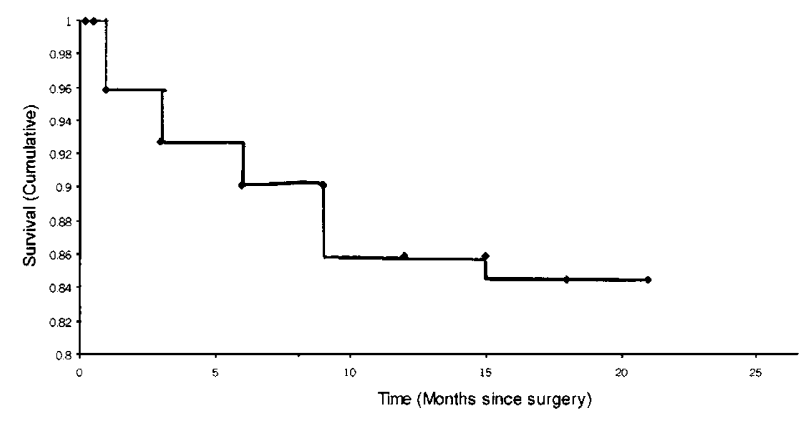

Figure 2 Cumulative probability of success following Ahmed Glaucoma Valve implantation was $85.95 \%$ at 12 months and $82.83 \%$ at 24 months. (Kaplan-Meier life-table analysis)

The Kaplan-Meier life-table analysis revealed an overall mean cumulative probability of success of $85.95 \%$ at 12 months and $82.83 \%$ at 24 months for all eyes (Figure 2).

Of the 122 eyes in this study only one eye had a visually devastating complication postoperatively that is, retinal detachment with no perception of light (Table 3). The most common complication was cornea-tube contact, which occurred in five $(4.10 \%)$ of the 122 eyes. In all these cases, the tube caused a superiorly localized corneal opacity that was not visually significant. None of these eyes had subsequent corneal decompensation. The corneal graft in two patients with postpenetrating keratoplasty glaucoma remained clear till their last follow-up noted in this study.

Other complications (Table 3 ) included four (3.27\%) eyes with postoperative hypotony (OIP $\leq 5 \mathrm{mmHg}$ ) during the first postoperative week, which resolved spontaneously by 2 weeks without any surgical intervention. One patient had choroidal effusion and shallowing of the anterior chamber, which resolved after tube revision during the second postoperative week. The tube revision was performed by trimming the intraocular portion of the tube and placing a releasable 10-0 nylon suture $^{29}$ around the portion of the tube beneath the scleral flap with one end of the suture externalized on the cornea. This suture was released after 1 week subsequent to resolution of the hypotony and associated choroidal effusion. Another patient had a wound leak with resultant hypotony and shallowing of the anterior chamber, which promptly resolved with wound revision and relatively tight suturing in the first postoperative week.

Two patients had a noticeable limitation of extreme upgaze after implant placement. Neither of these two patients were symptomatic or required subsequent strabismus surgery.

Two patients had tube extrusion, which required tube repositioning and reinforcement with a scleral patch
Table 3 Postoperative complications

\begin{tabular}{lll}
\hline Sl.no. & Complication & No. (\%) \\
\hline 1 & Tube-cornea contact & $05(4.10)$ \\
2 & Hypotony & $04(3.27)$ \\
3 & Vitreous blocking tube & $03(2.46)$ \\
4 & Hyphaema $>1 \mathrm{~mm}$ & $03(2.46)$ \\
5 & Tube extrusion & $02(1.64)$ \\
6 & Uveitis with fibrinous pupillary & \\
& membrane & $02(1.64)$ \\
7 & Motility disorders & $02(1.64)$ \\
8 & Choroidal effusion with shallow & \\
& anterior chamber & $01(0.82)$ \\
9 & Wound leak & $01(0.82)$ \\
10 & Subconjunctival haemorrhage & $01(0.82)$ \\
11 & Cataract development/progression & $01(0.82)$ \\
12 & Retinal detachment & $01(0.82)$ \\
\hline
\end{tabular}

graft. Notably, only one eye among the phakic patients developed progression of cataract. No case of blebitis or endophthalmitis, malignant glaucoma, or persistent anterior chamber inflammation was seen. Two patients with uveitic glaucoma developed a fibrinous pupillary membrane in the immediate postoperative requiring an increase in the steroid dosage. Posterior encapsulation of the bleb was not noted in any patient as a complication till the period of last follow-up.

Visual acuity remained stable (ie within one Snellen line of preoperative levels in cases wherever quantitative visual acuity measurement was possible) at last followup in all cases $(98.4 \%)$ except for two eyes, one of which developed progression of cataract and the other had retinal detachment. The visual acuity assessment for comparison was performed after a minimum follow-up of 3 months.

\section{Discussion}

The management of refractory glaucomas has considerably improved over the last 2 decades with advances in glaucoma drainage implant surgery. ${ }^{1}$ Such devices allow a large surface area reservoir for the drainage of aqueous humour and provide a mechanism whereby aqueous humour may bypass excessive scar tissue formation at the limbus. A variety of these drainage implants have been developed, including open tube and valved designs..$^{1,7,30-33}$ The Ahmed Glaucoma Valve implant is a valved polypropylene tube implant, which is designed to provide resistance to aqueous flow and decrease chances of severe postoperative hypotony that may be associated with the use of these devices. ${ }^{1-5}$ This valved implant has been used in many subsets of the population with varying ethnic backgrounds with satisfactory results..$^{2-6,8,13,16,26,27,34-36}$ Clinical features and progression of the glaucomatous process as well as 
response to surgery have been found to be different in people of different ethnic origins. ${ }^{37-39}$ Glaucoma drainage devices used in Asian eyes, mainly Chinese, have been found to show responses similar to those seen in non-Asian eyes..$^{2-6,8}$ We analysed the response to surgery (with the modifications in surgical technique mentioned in the Material and Methods section) with the Ahmed Glaucoma Valve implant in Indian eyes with refractory glaucomas to assess the efficacy and safety of this procedure in our population.

In the present study, the cumulative probability of success of Ahmed Glaucoma Valve placement in the present study was $86.91 \%$ at 12 months and $83.76 \%$ at 24 months. These values compare favourably to those reported by other investigators using the same Ahmed Glaucoma Valve implant in both Asian and non-Asian subsets of the population. 2,5,8,9,16,30,35 The cumulative probability of success at 2 years varied between 58 and $86 \%$ in different studies. Any differences could possibly be accounted for by the differences in the surgical technique, in the study population, in the follow-up period, and in the criteria for success taken up by different investigators. The sudden drop in the success rate at 2 years was particularly seen in the paediatric population undergoing this procedure. ${ }^{12-14}$

The visual acuity improved or remained within one Snellen line of the preoperative value in different studies, ${ }^{3,5,9,10,12-16}$ which was undoubtedly influenced by the relative proportion of glaucoma types in the abovementioned studies. The postoperative visual acuity in our study also showed no significant change from the preoperative levels in $98.4 \%$ eyes at last follow-up, though change in visual acuity was not a criterion for success or failure in this study. There was only one visually devastating complication in the present study, a retinal detachment in a patient with Eale's disease, and secondary neovascular glaucoma, at 3 months postoperatively, probably as a result of aggravation of the underlying proliferative vitreoretinopathy. Other sightthreatening retinal complications has been noted after the Ahmed valve implantation, ${ }^{40}$ but these were not seen in patients in our study group.

A period of transient elevation of IOP termed the 'hypertensive phase' has been described after aqueous drainage device surgeries. ${ }^{5,10,30-32}$ This has been noted most commonly to occur after 4 weeks postoperatively and has been seen to last for about 12 weeks after surgery. In the present study, however, we did not see this 'hypertensive phase'. This could probably be due to the surgical modification of the procedure we performed where we made a partial thickness scleral flap prior to the insertion of the Ahmed valve. The complementary continuous egression of aqueous through the dissected scleral flap could possibly contribute to equivocal distribution of the IOP over the postoperative period and the absence of this phase in our patients. The absence of the hypertensive phase has also been seen after the use of the Baerveldt valve, ${ }^{34}$ possibly due to its larger plate surface area and consequent equivalent drainage of aqueous at all times during the postoperative period. Besides, the use of postoperative antiglaucoma medications may have also obtunded the hypertensive phase in our study.

The most common complication in our study was tube-cornea contact, which occurred in five $(4.10 \%)$ out of 122 eyes. The tube contact tended to occur in buphthalmic eyes of very young patients, perhaps because of reduced scleral rigidity and anterior migration of the tube with postoperative IOP reduction, which allowed shrinkage of the stretched sclera and globe. The rate of tube-cornea contact, especially in paediatric patients in our series, is comparable to that reported by others using the same valve implant. ${ }^{12-15}$ It should be emphasized that in paediatric patients, growth of the eye might lead to retraction of the tube out of the anterior chamber and associated strabismus due to smaller orbital volume available. Therefore, in paediatric patients, ultrasonic biometry should be carried out to decide about the size of the implant to be used according to the size of the globe. A smaller paediatric model (S-3) is usually preferred in such cases.

Another reason for the high tube-cornea contact rate in the present study might also be due to the fact that the anterior chamber was artificially inflated with viscoelastics during the implantation. This may have led to mild distortion of the anterior chamber anatomy postoperatively and inappropriate physiological positioning of the tube in some cases.

The main potential weakness of tube implant surgery is long-term encapsulation. The Ahmed Glaucoma valve, because of its small surface area and polypropylene material, ${ }^{5,8}$ is potentially at higher risk of encapsulation than implants such as the Baerveldt shunt, ${ }^{34}$ which has a large surface area and silicone plate. Posterior encapsulation has been described as the most common complication of Ahmed valve implantation in an Asian, predominantly Chinese study population. ${ }^{8}$ However, this complication was not seen in any patient in our study. The possible reason for this could be the relatively shorter recorded follow-up period of the patients or a possibly a less aggressive tissue healing process in Indian eyes. The latter hypothesis is presumptive and would need substantiation by further randomized clinical trails taking the response to surgery in different races into account.

There were four (3.27\%) cases of hypotony and two cases of shallow anterior chamber in our study, which is less than what has been reported with other implants in 
various studies. ${ }^{8,29-34}$ Huang et $a l^{5}$ reported a transient postoperative hypotony ( $8 \%$ ) with the Ahmed implant. This emphasizes the possible protective effect of the valve mechanism of the Ahmed Glaucoma Valve implant in reducing postoperative hypotony and shallow anterior chamber in our study. An additional factor leading to the lesser incidence of hypotony in the present study could be due to the use of viscoelastics to form the anterior chamber prior to insertion of the tube and keeping the chamber formed with the help of BSS at the end of the surgery through the paracentesis incision. Considering that making the partial thickness scleral bed (similar to that made in a non penetrating deep sclerectomy) for the valve tube to rest on, which could also be contributing to the hypotensive effect of the surgery, it is possible that the incidence of shallow anterior chambers and hypotony would have been higher in our study group if we had not reformed the anterior chamber prior to completion of the surgery. An unusual cause of shallowing of the anterior chamber after concomitant Ahmed valve implantation and cataract extraction has been described in the literature, which was considered to be due to the distension of the capsular bag as a result of probable entrapment of viscoelastics, thus making this unusual diagnosis of the capsular bag distention syndrome a differential of postoperative shallow anterior chamber after the Ahmed valve implantation. ${ }^{41}$

Two $(1.64 \%)$ patients had a noticeable limitation of extreme upgaze after implant placement in this study but were asymptomatic and required no strabismus surgery. The Ahmed Glaucoma Valve implant should be placed preferentially in the superotemporal quadrant as implantation of a large implant in the superonasal quadrant can lead to pseudo-Brown's syndrome ${ }^{42}$ and has potential for contact with the optic nerve. ${ }^{43}$

Ahmed Glaucoma Valve implantation appears to be a viable option for management of refractory glaucoma in Indians, with an overall cumulative probability of success being $83.76 \%$ at 24 months, which is comparable to that previously reported. ${ }^{5,8}$ The Ahmed valve has been used both as a primary and a secondary modality of treatment for different subtypes of glaucoma, ${ }^{2,3}$ and also concomitantly with other procedures like penetrating keratoplasty ${ }^{26-28}$ and cataract extraction. ${ }^{36,41,44}$ Different modifications such as concomitant use of mitomycin$\mathrm{C}^{6,35}$ partial Tenon's capsule resection to prevent formation of encapsulated blebs, ${ }^{35}$ modifications in the shape $^{45}$ and size of the Ahmed Glaucoma Valve implant have all been used to improve success rates with the use of this valve in difficult clinical situations.

We had previously conducted a study on combined cataract extraction with implantation of the Ahmed Valves in Indian patients with phacomorphic glaucoma, which is the only Indian study on this procedure. ${ }^{36}$ The results of the present series co-relate well with this previous study ${ }^{36}$ in terms of intraocular pressure control, complication rates, and the visual outcome with the majority of postoperative complications being transient and self-resolving. In conclusion, this study reemphasizes the role of the Ahmed Glaucoma Valve implant as a safe and effective modality of treatment for complicated glaucomas in the Indian population.

\section{References}

1 Leuenberger EU, Grosskreutz CL, Walton DS, Pasquale LR. Advances in aqueous shunting procedures. Int Ophthalmol Clin 1999; 39(1): 139-153.

2 Wilson MR, Mendis U, Paliwal A, Haynatzka V. Long term follow-up of primary glaucoma surgery with Ahmed glaucoma implant versus trabeculectomy. Am J Ophthalmol 2003; 136(3): 464-470.

3 Wilson MR, Mendis U, Smith SD. Ahmed Glaucoma Valve implant $v$ s trabeculectomy in the surgical treatment of glaucoma: a randomized clinical trial. Am J Ophthalmol 2000; 130: $267-273$.

4 Coleman AL, Hill R, Wilson MR, Choplin N, KotasNeumann R, Tam $\mathrm{M}$ et al. Initial clinical experience with the Ahmed Glaucoma Valve implant. Am J Ophthalmol 1995; 120: 23-31.

5 Huang MC, Netland PA, Coleman AL, Siegner SW, Moster MR, Hill RA. Intermediate-term clinical experience with the Ahmed Glaucoma Valve implant. Am J Ophthalmol 1999; 127(1): 27-33.

6 Kook MS, Yoon J, Kim J, Lee MS. Clinical results of Ahmed Glaucoma Valve Implantation in Refractory Glaucoma with adjunctive Mitomycin C. Ophthalmic Surg Lasers 2000; 31(02): 100-106.

7 Ayyala RS, Zurakowski D, Monshizadeh R, Hong CH, Richards D, Layden WE et al. Comparison of double-plate Molteno and Ahmed glaucoma valve in patients with advanced uncontrolled glaucoma. Ophthalmic Surg Lasers 2002; 33(2): 94-101.

8 Lai JS, Poon AS, Chua JK, Tham CC, Leung AT, Lam DS. Efficacy and safety of the Ahmed Glaucoma Valve implant in Chinese eyes with complicated glaucoma. Br J Ophthalmol 2000; 84(7): 718-721.

9 Topouzis F, Coleman AL, Choplin N, Bethlem MM, Hill R, $\mathrm{Yu} \mathrm{F}$ et al. Follow-up of the original cohort with the Ahmed Glaucoma Valve implant. Am J Ophthalmol 1999; 128(2): 198-204.

10 Ayyala RS, Zurakowski D, Smith JA, Monshizadeh R, Netland PA, Richards DW et al. A clinical study of the Ahmed Glaucoma Valve implant in advanced glaucoma. Ophthalmology 1998; 105(10): 1968-1976.

11 Netland PA, Walton DS. Glaucoma drainage implants in pediatric patients. Ophthalmic Surg 1993; 24: 723.

12 Englert JA, Freedman SF, Cox TA. The Ahmed valve in refractory pediatric glaucoma. Am J Ophthalmol 1999; 127: $34-42$.

13 Djodeyre MR, Calvo JP, Gomez JA. Clinical evaluation and risk factors of time to failure of Ahmed Glaucoma Valve Implant in pediatric patients. Ophthalmol 2001; 108: 614-620.

14 Morad Y, Donaldson CE, Kim YM, Abdolell M, Levin AV. The ahmed drainage Implant in the treatment of pediatric glaucoma. Am J Ophthalmol 2003; 135: 821-829. 
15 Coleman AL, Smyth RJ, Wilson MR, Tam M. Initial clinical experience with the Ahmed Glaucoma Valve implant in pediatric patients. Arch Ophthalmol 1997; 115: 186-191.

16 Hill R, Ohanesian R, Voskanyan L, Malayan A. The Armenian Eye care project: surgical outcomes of complicated pediatric glaucoma. Br J Ophthalmol 2003; 87(6): 673-676.

17 Hamish NG, Coleman AL, Wilson MR. Ahmed Glaucoma Valve implant for the management of glaucoma in Sturge Weber syndrome. Am J Ophthalmol 1999; 128: 758-760.

18 Lee WB, Brandt JD, Mannis MJ, Huang CO, Robin GJ. Aniridia and Brachmann-de-Lange syndrome: a review of ocular surface and anterior segment findings. Cornea 2003; 22(2): 178-180.

19 Sidoti PA, Dunphy TR, Baerveldt G, LaBree L, Minckler DS, Lee PP. Experience with the Baerveldt glaucoma implant in treating neovascular glaucoma. Ophthalmology 1995; 102: 1107.

20 Da Mata A, Burk SE, Netland PA, Baltatzis S, Christen W, Foster CS. Management of uveitic glaucoma with Ahmed Glaucoma Valve implantation. Ophthalmology 1999; 106(11) 2168-2172.

21 Da Mata AP, Foster CS. Ahmed valve and uveitic glaucoma. Int Ophthalmol Clin 1999; 39(1): 155-167.

22 Gil-Carrasco F, Salinas-VanOrman E, Recillas-Gispert C, Paczka JA, Gilbert ME, Arellanes-Garcia L. Ahmed valve implant for uncontrolled uveitic glaucoma. Ocul Immunol Inflamm 1998; 6(1): 27-37.

23 Varma R, Heuer DK, Lundy DC, Baerveldt G, Lee PP, Minckler DS. Pars Plana Baerveldt tube insertion with vitrectomy in glaucomas associated with pseudophakia and aphakia. Am J Ophthalmol 1995; 119: 401

24 Gandham SB, CostaVP, Katz LJ, Wilson RP, Sivalingam A, Belmont J. Aqueous tube-shunt implantation and pars plana vitrectomy in eyes with refractory glaucoma. Am J Ophthalmol 1993; 116: 189.

25 Sherwood MB, Smith MF, Driebe Jr WT, Stem GA, Beneke JA, Zam ZS. Drainage tube implants in the treatment of glaucoma following penetrating keratoplasty. Ophthalmology 1988; 24: 185.

26 Al-Torbak A. Graft survival and glaucoma outcome after simultaneous penetrating keratoplasty and Ahmed Glaucoma Valve implant. Cornea 2003; 22(3): 194-197.

27 Zacharia PT, Harrison DA, Wheeler DT. Penetrating keratoplasty with a valved glaucoma drainage implant for congenital glaucoma and corneal scarring secondary to hydrops. Ophthalmic Surg Lasers 1998; 29(4): 318-322.

28 Coleman AL, Mondino BJ, Wilson MR, Casey R. Clinical experience with the Ahmed Glaucoma Valve implant in eyes with prior or concurrent penetrating keratoplasties. Am J Ophthalmol 1997; 123(1): 54-61.

29 Sayyad FE, El Maghraby A, Helal M, Amayem A. The use of releasable sutures in Molteno implant procedures to reduce postoperative hypotony. Ophthalmic Surg 1991; 22: 82.

30 Minckler DS, Heuer DK, Hasty B, Baerveldt G, Cutting RC, Barlow WE. Clinical experience with the single-plate
Molteno implant in complicated glaucomas. Ophthalmology 1988; 95: 1181-1188.

31 Fellenbaum PS, Almeida AR, Minckler DS, Sidoti PA, Baerveldt G, Heuer DK. Krupin disk implantation for complicated glaucoma. Ophthalmology 1994; 101: 1178-1182.

32 Leiberman MF, Ewing RH. Drainage implant surgery for refractory glaucoma. Int Ophthalmol Clin 1990; 30: 198-208.

33 Siegner SW, Netland PA, Urban RC, Williams AS, Richards DW, Latina MA. Clinical experiences with the Baerveldt glaucoma drainage implant. Ophthalmology 1995; 102: 1298-1307.

34 Aung T, Seah SKL. Glaucoma drainage implants in Asian eyes. Ophthalmology 1998; 105: 2117-2122.

35 Susanna R. Latin American Glaucoma Society Investigators. Partial Tenon's capsule resection with adjunctive mitomycin $\mathrm{C}$ in Ahmed Glaucoma Valve implant surgery. $\mathrm{Br} \mathrm{J}$ Ophthalmol 2003; 87(8): 994-998.

36 Das JC, Chaudhuri Z, Bhomaj S, Sharma P, Gupta R, Chauhan D. Combined extracapsular cataract extraction with Ahmed Glaucoma valve implantation in phacomorphic glaucoma. Indian J Ophthalmol 2002; 50(1): 25-28.

37 Rosman M, Aung T, Ang LP, Chew PT, Leibmann JM, Ritch R. Chronic angle-closure with glaucomatous damage: longterm clinical course in a North American population and comparison with an Asian population. Ophthalmology 2002; 109(12): 2227-2231.

38 Beck AD. Advanced glaucoma intervention study. Review of recent publications of the advanced glaucoma intervention study. Curr Opin Ophthalmol 2003; 14(2): 83-85.

39 AGIS Investigators. The Advanced Glaucoma Intervention Study (AGIS): 9. Comparison of glaucoma outcomes in black and white patients within treatment groups. Am J Ophthalmol 2001; 132(3): 311-320.

40 Law SK, Kalenak JW, Connor Jr TB, Pulido JS, Han DP, Mieler WF. Retinal complications after aqueous shunt surgical procedures for glaucoma. Arch Ophthalmol 1996; 114(12): 1473-1480.

41 McQueen BR, Margo CE. Capsular bag distention syndrome after combined cataract-lens implant surgery and ahmed valve implantation. Am J Ophthalmol 2001; 132: 109-110.

42 Coats DK, Paysse EA, Orenga-Nania S. Acquired pseudoBrown's syndrome immediately following Ahmed Valve Glaucoma implant. Ophthalmic Surg Lasers 1999; 30(5): 396-397.

43 Leen MM, Whitkop GS. Anatomic considerations in the implantation of the Ahmed Glaucoma Valve. Arch Ophthal 1996; 114: 223-224.

44 Hoffman KB, Feldman RM, Budenz DL, Gedde SJ, Chacro GA, Schiffman JC. Combined cataract extraction and Baerveldt glaucoma drainage implant: indications and outcomes. Ophthalmology 2002; 109(10): 1916-1920.

45 Latina MA, Gulati V. A Modification of the Ahmed valve for tight places. Oph Surg, Lasers,Imaging 2003; 34: 396-397. 